\title{
Generation Means Analysis for Quantitative Traits in Sesame (Sesamum indicum L.)
}

\author{
Kanak Saxena* and Rajani Bisen \\ Department of Plant breeding and Genetics, Jawaharlal Nehru Krishi Vishwavidyalaya, \\ Jabalpur (M.P) 482004, India \\ *Corresponding author
}

\section{A B S T R A C T}

\section{Keywords}

Sesame, Quantitative trait, Scaling tests,

Gene effects, Bi-

parental mating

Article Info

Accepted:

04 July 2018

Available Online:

10 August 2018
To study the nature and magnitude of gene effects for yield and its components in sesame (Sesamum indicum L.) we carried out generation mean analysis using the following five crosses of different sesame cultivars: TKG-503 X GT-10; RT-373 X GT-2; JLS-613-1-1 X GT-10; MT-10 X GT-2 and AT-253 X TKG-22. The $\mathrm{P}_{1}, \mathrm{P}_{2}, \mathrm{~F}_{1}, \mathrm{~F}_{2}$, and $\mathrm{F}_{3}$ of these generations were studied for twelve quantitative traits. The analysis showed the presence of additive, dominance and epistatic gene interactions. The additive dominance model was adequate for days to $50 \%$ flowering and plant height in all the five crosses, for seeds per capsule and seed yield per plant in two crosses JLS-613-1-1 X GT-10 and AT-253 X TKG-22. Duplicate-type epistasis played a greater role than complementary epistasis. The study revealed the importance of both additive and non-additive types of gene action for all the traits studied.

\section{Introduction}

Sesame (Sesamum indicum L.), commonly known as gingelly, til, simsim, a member of family pedaliaceae. Although originated in Africa, it spread early through West Asia to India, China and Japan which themselves became secondary distribution centres (Weiss, 1983). It is called as the "Queen of oil seeds" because of its excellent qualities of the seed, oil and meal. Sesame is highly nutritive (oil $50 \%$, protein $25 \%$ ) and its oil contains an antioxidant called sesamol which imparts a high degree of resistance against oxidative rancidity. Sesame cake is nutritious feed for dairy cattle and it can also be used as fertilizer
(Ashri, 1989). Sesame is the most neglected oil seed crop grown on marginal lands under poor management resulting in very low yield (Cagrgan, 2006). Further, the poor yield is due to the non-availability of cultivars to suit the diverse agro-climatic conditions. Hence, development of improved high yielding cultivars adapted to local conditions has become top priority.

It is an important annual oilseed crop in the tropics and warm subtropics, where it is usually grown in small patches. In India, sesame is cultivated in an area of 19.53 lakh hectares with an annual production of 8.32 lakh tonnes and productivity of $426.4 \mathrm{~kg} / \mathrm{ha}$ 
(Anonymous, 2015-16). In Madhya Pradesh it is grown in an area of 3.85 lakh hectares with an annual production 1.97 lakh tonnes and productivity of $540 \mathrm{~kg} / \mathrm{ha}$, respectively. The present sesame varieties under cultivation have limited yield potential. This indicates the need to enhance the productivity of this crop by developing high yielding genotypes, which depend on the availability of variability for yield and its component traits in the populations. Sesame has a wide range of genetic variability in its extensive germplasm collections. However, certain highly desirable traits have not been found so far, including good seed retention and resistance to certain diseases (Ashri, 1998).

For genetic improvement of the crop, the breeding method to be adopted depends mainly on the nature of gene action involved in the expression of quantitative trait. Line $\mathrm{x}$ Tester $(\mathrm{L} \times \mathrm{T})$ analysis is used to select the parents based on their combining ability but fails to detect the epistasis, which remains the most complex problem and on which it is extremely difficult to obtain reliable results. The inherent drawback of $\mathrm{L} \times \mathrm{T}$ design is that, it estimates additive and dominance components of gene action only and information on epistasis cannot be estimated which is an integral component of genetic architecture of population. So, information on the presence of type of epistatic genetic effects in the inheritance of various quantitative traits is important for adopting suitable breeding procedures to improve the traits. Generation mean analysis (Hayman, 1958) gives a comprehensive picture of gene action controlling the trait. The presence or absence of epistasis can be detected by the analysis of generation means using the scaling test, which measures epistasis accurately whether it is complimentary (Additive $\mathrm{x}$ Additive) or duplicate (Additive $x$ Dominance) and (Dominance $\mathrm{x}$ Dominance) at the digenic level. It is relatively a simple first degree statistically analyzed technique to know the predominant genetic effects that are responsible in effecting the variation of character. In this area of generation mean analysis in sesame very little work has been done in India and abroad. Therefore, the present investigation was made with objective to estimate gene action through generation mean analysis.

\section{Materials and Methods}

Ten Sesamum indicum L. cultivars (TKG-478, TKG-503, RT-373, MT-10, AT-253, TKG506, AT-306, AT-307, JLS-613-1-1, AT-324, TKG-21, TKG-22, GT-2 and GT-10) collected from different agro morphological regions of India were used as experimental material. These selected parents were crossed in L x T fashion to generate 40 hybrids in kharif, 2015 These 40 crosses along with their parents were evaluated in Summer, 2015-16. From the above 40 crosses, five promising crosses were selected and and also $F_{1}$ hybrid are selfed to produce $F_{2}$ seed in Summer, 2015-16. The part of the $F_{2}$ seed is saved and part of the $F_{2}$ seed was advanced to generate $F_{3}$ for generation mean analysis during kharif, 2016.

All the five populations (P1, P2, F1, F2 and $\mathrm{F}_{3}$ ) had to be grown together in randomized block design (RBD) with three replications in Project Co-ordinating Unit (Sesame and Niger), JNKVV, Jabalpur (M.P.) during Summer, 2016-17. The experiments involved the five basic generations (the P1 and P2 parent cultivars, the F1, F2 and F3 first, second and third filial generations) of five combinations of the parental cultivars, these combinations being TKG-503 X GT-10, RT373 X GT-2, JLS-613-1-1 X GT-10, MT-10 X GT-2 and AT-253 X TKG-22.

The mean values, standard errors and variances of the of the parents $\left(\mathrm{P}_{1} \& \mathrm{P}_{2}\right), \mathrm{F}_{1}, \mathrm{~F}_{2}$ and $F_{3}$ generations of each cross were utilized 
to work out the probable gene action involved in the material for each character. Five crosses were analyzed using Joint scaling test (Cavalli, 1952) for twelve characters to estimate the main gene effects $[m, d, h]$ and also to seek the evidence of epistasis. The additive-dominance model as tested by joint scaling test was not satisfactory for all the crosses. Based on significance of chi-square values obtained by Joint scaling test (Cavalli, 1952), epistasis was indicated in all the crosses for all the traits studied. Consequently, five parameter model (Hayman, 1958, Jinks and Jones, 1958) was applied to estimate the gene effects in all the crosses. The five parameters were mean $[m]$, the main gene effects, additive $[d]$ and dominance $[h]$ and two epistatic interactions i.e. additive $\times$ additive $[i]$ and dominance $\times$ dominance $[l]$. The type of epistasis was determined only when dominance $(h)$ and dominance $\times$ dominance $(l)$ effects were significant, when these effects had the same sign the effects were complementary while different signs indicated duplicate epistasis (Kearsey and Pooni 1996).

\section{Results and Discussion}

The mean and standard error of the five generations with five crosses were analyzed for generation mean analysis for twelve traits are presented in Table 1. The mean of the five generations i.e. $\mathrm{P}_{1}, \mathrm{P}_{2}, \mathrm{~F}_{1}, \mathrm{~F}_{2}$ and $\mathrm{F}_{3}$ of each cross were utilized to work out the probable gene action involved in the material for each character. The additive-dominance model as tested by joint scaling test was not satisfactory for all the crosses. Thus, based on nonsignificant $\chi^{2}$ value some of the characters were within adequacy of 3 parameter additive dominance model classified for additive $[d]$ and dominance $[h]$ type of gene actions. However, $\chi^{2}$ values were significant, only under digenic epistatic model for five parameter test, the characters are grouped under various mean $[m]$, additive $[d]$, dominance $[h]$ and additive $\times$ dominance $[j]$ types of gene action.

The additive, dominance and epistatic types of gene interaction in each cross for different trait were found to be different from each other. The dominance $\times$ dominance interaction $[l]$ was larger than the additive $\times$ additive [ $i]$ effects, while for the main effects the dominance component $(\mathrm{h})$ was greater than the additive $[d]$ component. The dominance $[h]$ and dominance $\times$ dominance $(l)$ effects were in the opposite direction, suggesting that duplicate-type epistasis occurred in most cases and indicating predominantly dispersed alleles at the interacting loci (Jinks and Jones 1958). Dominance gene effects were found to be relatively more important, as indicated by the fact that in all cases the dominance $[h]$ values were higher than the additive $[d]$ values. The results indicated that the mean effects $[\mathrm{m}]$ of the five sesame crosses were positive and significant for all the crosses for all the traits, indicating that these traits are quantitatively inherited. Similar results were also reported by Sundari et al., (2012), Jaloth et al., (2013) and Ali et al., (2015).

The 'days to 50 percent flowering' trait shows that the dominance gene effects $[h]$ was in negative direction except for JLS-613-1-1 X GT-10 and AT-253 X TKG-22 indicating thereby dominance for earliness. Among the three epistatic effects, the significant dominance $\mathrm{x}$ dominance interaction $[l]$ were showed by JLS-613-1-1 X GT-10, MT-10 X GT-2 and AT-253 X TKG-22.

Predominant role of dominant gene action in the expression of days to flowering have been reported by Anbanandan et al., (2006), Sumathi and Murlidharan (2010b). Anbanandan et al., (2006) also reported role of dominance $\mathrm{x}$ dominance epistasis in the inheritance of days to flowering 
Table.1 Mean and their standard error of five generations with five crosses for twelve traits

\begin{tabular}{|c|c|c|c|c|c|}
\hline Crosses & {$[\hat{\mathrm{m}}]$} & {$[\hat{\mathrm{d}}]$} & {$[\hat{\mathrm{h}}]$} & {$[\hat{\mathrm{i}}]$} & {$[\hat{1}]$} \\
\hline \multicolumn{6}{|c|}{ Days to $50 \%$ flowering } \\
\hline TKG-503 X GT-10 & $49.67 * * \pm 0.31$ & $2.00 * * \pm 0.15$ & $-13.33 * \pm 0.87$ & $-1.34 * * \pm 0.27$ & $3.33 * * \pm 0.61$ \\
\hline RT-373 X GT-2 & $43.17 * * \pm 0.44$ & $0.50 * * \pm 0.15$ & $-11.17 * \pm 1.21$ & $-2.67 * * \pm 0.41$ & $5.67 * * \pm 1.00$ \\
\hline JLS-613-1-1 X GT-10 & $35.83 * * \pm 0.37$ & $-1.17 * * \pm 0.13$ & $4.50 * * \pm 0.95$ & $3.13 * * \pm 0.35$ & $-4.33 * * \pm 0.72$ \\
\hline MT-10 X GT-2 & $17.67 * * \pm 0.45$ & $0.33 * \pm 0.13$ & $-16.67 * \pm 1.07$ & $2.82 * * \pm 0.44$ & $-6.67 * * \pm 0.88$ \\
\hline AT-253 X TKG-22 & $34.17 * * \pm 0.36$ & $1.17 * * \pm 1.18$ & $9.50 * * \pm 0.91$ & $5.33 * * \pm 0.31$ & $-3.67 * * \pm 0.70$ \\
\hline \multicolumn{6}{|c|}{ Plant height $(\mathrm{cm})$} \\
\hline TKG-503 X GT-10 & $154.21 * * \pm 1.94$ & $-1.34 \pm 0.87$ & $-37.34 * \pm 5.81$ & $-19.49 * \pm 1.73$ & $18.78 * \pm 4.17$ \\
\hline RT-373 X GT-2 & $155.76^{* * \pm 2.34}$ & $2.92 * * \pm 0.69$ & $-31.08 * \pm 6.12$ & $-12.73 * \pm 2.24$ & $11.18 * \pm 4.34$ \\
\hline JLS-613-1-1 X GT-10 & $71.72 * * \pm 1.80$ & $7.54 * * \pm 0.64$ & $36.36 * * \pm 5.04$ & $35.77 * * \pm 1.69$ & $-53.97 * \pm 3.52$ \\
\hline MT-10 X GT-2 & $103.84 * * \pm 1.97$ & $12.87 * * \pm 0.68$ & $28.06 * * \pm 5.68$ & $29.23 * * \pm 1.85$ & $-47.09 * \pm 4.09$ \\
\hline AT-253 X TKG-22 & $78.59 * * \pm 1.67$ & $-4.11 * * \pm 0.73$ & $45.10 * * \pm 4.52$ & $41.72 * * \pm 1.50$ & $-48.25^{*} \pm 3.60$ \\
\hline \multicolumn{6}{|c|}{ Number of primary branches per plant } \\
\hline TKG-503 X GT-10 & $12.17 * * \pm 0.28$ & $6.55 * * \pm 0.13$ & $8.80 * * \pm 0.76$ & $-5.47 * * \pm 0.17$ & $5.60 * * \pm 0.55$ \\
\hline RT-373 X GT-2 & $8.20 * * \pm 0.21$ & $-0.32 * * \pm 0.12$ & $-1.43^{*} \pm 0.61$ & $-1.20 * * \pm 0.11$ & $-1.32 * \pm 0.44$ \\
\hline JLS-613-1-1 X GT-10 & $6.21 * * \pm 0.15$ & $-0.22 * * \pm 0.07$ & $4.62 * \pm 0.40$ & $0.47 * * \pm 0.08$ & $1.43 * * \pm 0.29$ \\
\hline MT-10 X GT-2 & $8.85 * * \pm 0.15$ & $0.28 * * \pm 0.09$ & $3.18 * * \pm 0.40$ & $-2.13 * * \pm 0.10$ & $2.77 * * \pm 0.29$ \\
\hline AT-253 X TKG-22 & $6.70 * * \pm 0.14$ & $0.27 * * \pm 0.05$ & $2.47 * * \pm 0.38$ & $1.07 * * \pm 0.07$ & $2.93 * * \pm 0.26$ \\
\hline \multicolumn{6}{|c|}{ Number of secondary branches per plant } \\
\hline TKG-503 X GT-10 & $14.27 * * \pm 0.28$ & $7.31 * * \pm 0.07$ & $9.12 * * \pm 0.61$ & $4.61 * * \pm 0.10$ & $4.40 * * \pm 0.65$ \\
\hline RT-373 X GT-2 & $7.09 * * \pm 0.12$ & $0.17 * * \pm 0.09$ & $1.20 * \pm 0.38$ & $0.78 * * \pm 0.16$ & $-0.13 * \pm 0.24$ \\
\hline JLS-613-1-1 X GT-10 & $8.24 * * \pm 0.14$ & $-0.37 * * \pm 0.12$ & $-0.12 * \pm 0.44$ & $-0.62 * * \pm 0.08$ & $1.45 * * \pm 0.28$ \\
\hline MT-10 X GT-2 & $9.91 * * \pm 0.17$ & $0.41 * * \pm 0.05$ & $1.24 * * \pm 0.52$ & $1.72 * * \pm 0.17$ & $1.58 * * \pm 0.35$ \\
\hline AT-253 X TKG-22 & $7.45 * * \pm 0.21$ & $0.29 * * \pm 0.15$ & $4.62 * * \pm 0.76$ & $1.13 * * \pm 0.11$ & $1.73 * * \pm 0.31$ \\
\hline \multicolumn{6}{|c|}{ Number of capsules per plant } \\
\hline TKG-503 X GT-10 & $136.88 * * \pm 6.07$ & $23.75 * * \pm 5.71$ & $66.45 * * \pm 18.03$ & $-25.00 * * \pm 2.04$ & $31.50 * * \pm 12.53$ \\
\hline RT-373 X GT-2 & $203.33 * * \pm 2.31$ & $-11.90 * * \pm 0.84$ & $98.00 * * \pm 5.92$ & $-11.40 * * \pm 2.16$ & $19.33 * * \pm 5.52$ \\
\hline JLS-613-1-1 X GT-10 & $89.93 * * \pm 2.16$ & $-15.03 * * \pm 1.16$ & $78.27 * * \pm 6.02$ & $6.47 * * \pm 1.83$ & $-8.00 * * \pm 4.62$ \\
\hline MT-10 X GT-2 & $54.23 * * \pm 2.19$ & $-13.20 * * \pm 1.20$ & $87.20 * * \pm 6.18$ & $19.00 * * \pm 1.83$ & $11.30 * * \pm 4.41$ \\
\hline AT-253 X TKG-22 & $42.87 * * \pm 2.32$ & $-2.87 * * \pm 0.88$ & $69.63 * * \pm 6.43$ & $20.60 * * \pm 2.15$ & $21.70 * * \pm 4.87$ \\
\hline \multicolumn{6}{|c|}{ Capsule length(cm) } \\
\hline TKG-503 X GT-10 & $2.37 * * \pm 0.03$ & $-0.07 * * \pm 0.02$ & $0.19 * \pm 0.09$ & $0.15^{*} \pm 0.02$ & $0.11 \pm 0.08$ \\
\hline RT-373 X GT-2 & $2.12 * * \pm 0.05$ & $-0.12 * * \pm 0.04$ & $1.04 * * \pm 0.14$ & $0.40 * * \pm 0.03$ & $0.64 * * \pm 0.11$ \\
\hline JLS-613-1-1 X GT-10 & $3.11 * * \pm 0.06$ & $-0.02 \pm 0.03$ & $1.09 * * \pm 0.18$ & $0.29 * * \pm 0.53$ & $0.53 * * \pm 0.19$ \\
\hline MT-10 X GT-2 & $2.29 * * \pm 0.06$ & $-0.04 \pm 0.03$ & $-0.69 * * \pm 0.17$ & $-0.25 * * \pm 0.05$ & $-0.46 * * \pm 0.11$ \\
\hline AT-253 X TKG-22 & $2.92 * * \pm 0.06$ & $0.03 \pm 0.03$ & $-0.87 * * \pm 0.17$ & $-0.21 * * \pm 0.04$ & $0.51 * * \pm 0.18$ \\
\hline \multicolumn{6}{|c|}{ Days to maturity } \\
\hline TKG-503 X GT-10 & $95.83 * * \pm 0.34$ & $2.83 * * \pm 0.20$ & $-3.83 * * \pm 0.99$ & $0.67 * \pm 0.27$ & $3.00 * * \pm 0.76$ \\
\hline RT-373 X GT-2 & $91.50 * * \pm 0.35$ & $-3.50 * * \pm 0.09$ & $7.50 * * \pm 0.91$ & $5.33 * * \pm 0.35$ & $5.00 * * \pm 0.70$ \\
\hline JLS-613-1-1 X GT-10 & $87.17 * * \pm 0.37$ & $3.17 * * \pm 0.13$ & $18.83 * * \pm 0.96$ & $8.67 * * \pm 0.35$ & $-10.33 * * \pm 0.76$ \\
\hline MT-10 X GT-2 & $85.17 * * \pm 0.32$ & $-1.17 * * \pm 0.09$ & $25.50 * * \pm 0.79$ & $9.33 * * \pm 0.31$ & $15.17 * * \pm 0.62$ \\
\hline AT-253 X TKG-22 & $89.50 * * \pm 0.35$ & $0.50 * * \pm 0.15$ & $14.50 * * \pm 0.87$ & $4.00 * * \pm 0.31$ & $-11.00 * * \pm 0.67$ \\
\hline \multicolumn{6}{|c|}{ Seeds per capsule } \\
\hline TKG-503 X GT-10 & $59.50 * * \pm 0.72$ & $-3.67 * * \pm 0.43$ & $6.14 * * \pm 2.05$ & $-3.56 * * \pm 0.58$ & $9.82 * * \pm 1.48$ \\
\hline RT-373 X GT-2 & $39.70 * * \pm 1.56$ & $-2.27 * * \pm 0.35$ & $31.15 * * \pm 4.55$ & $20.64 * * \pm 1.53$ & $22.73 * * \pm 3.10$ \\
\hline JLS-613-1-1 X GT-10 & $46.05 * * \pm 1.08$ & $6.70 * * \pm 0.53$ & $35.43 * * \pm 2.82$ & $20.60 * * \pm 0.94$ & $-20.93 * * \pm 2.16$ \\
\hline MT-10 X GT-2 & $23.80 * * \pm 1.24$ & $-7.73 * * \pm 0.40$ & $84.50 * * \pm 3.13$ & $41.99 * * \pm 1.17$ & $48.00 * * \pm 2.35$ \\
\hline AT-253 X TKG-22 & $62.42 * * \pm 0.92$ & $-1.95 * * \pm 0.41$ & $6.09 * \pm 2.45$ & $6.82 * * \pm 0.82$ & $-7.10 * * \pm 1.82$ \\
\hline \multicolumn{6}{|c|}{ 1000-seed weight $(\mathrm{g})$} \\
\hline TKG-503 X GT-10 & $3.29 * * \pm 0.03$ & $0.11 \pm 0.01$ & $1.94 * * \pm 0.07$ & $-0.81 * * \pm 0.02$ & $1.22 * * \pm 0.07$ \\
\hline RT-373 X GT-2 & $2.79 * * \pm 0.05$ & $-0.09 * * \pm 0.03$ & $0.75 * * \pm 0.15$ & $-0.02 \pm 0.04$ & $0.41 * * \pm 0.11$ \\
\hline JLS-613-1-1 X GT-10 & $3.07 * * \pm 0.06$ & $0.03 \pm 0.03$ & $1.44 * * \pm 0.14$ & $0.34 * * \pm 0.05$ & $-0.68 * * \pm 0.10$ \\
\hline
\end{tabular}




\begin{tabular}{|c|c|c|c|c|c|}
\hline MT-10 X GT-2 & $1.88 * * \pm 0.05$ & $0.12 * * \pm 0.02$ & $1.10 * * \pm 0.14$ & $0.92 * * \pm 0.04$ & $1.36 * * \pm 0.09$ \\
\hline AT-253 X TKG-22 & $5.25 * * \pm 0.10$ & $0.09 * * \pm 0.02$ & $4.95 * * \pm 0.21$ & $2.39 * * \pm 0.09$ & $3.19 * * \pm 0.16$ \\
\hline \multicolumn{6}{|c|}{ Seed yield per plant (g) } \\
\hline TKG-503 X GT-10 & $11.71 * * \pm 0.38$ & $5.03 * * \pm 0.24$ & $0.41 \pm 1.12$ & $-1.40 * * \pm 0.30$ & $2.53 \pm 0.81$ \\
\hline RT-373 X GT-2 & $19.49 * * \pm 0.49$ & $0.95 * * \pm 0.17$ & $20.62 * * \pm 1.43$ & $8.65 * * \pm 0.46$ & $11.82 * * \pm 0.97$ \\
\hline JLS-613-1-1 X GT-10 & $4.24 * * \pm 0.43$ & $0.08 \pm 0.19 \mathrm{NS}$ & $14.14 * * \pm 1.12$ & $7.54 * * \pm 0.38$ & $-6.61 * * \pm 0.81$ \\
\hline MT-10 X GT-2 & $5.91 * * \pm 0.42$ & $-0.60 * \pm 0.23$ & $21.72 * * \pm 1.22$ & $6.48 * * \pm 0.35$ & $17.25^{* * \pm 0.87}$ \\
\hline AT-253 X TKG-22 & $30.39 * * \pm 0.47$ & $2.51 * * \pm 0.11$ & $-18.07 * * \pm 1.17$ & $18.14 * * \pm 0.46$ & $24.53 * * \pm 0.85$ \\
\hline \multicolumn{6}{|c|}{ Harvest index (\%) } \\
\hline TKG-503 X GT-10 & $17.46^{* * \pm 0} 0.44$ & $-6.00 * * \pm 0.18$ & $1.01 * * \pm 0.15$ & $-7.17 * * \pm 0.31$ & $14.12 * * \pm 0.88$ \\
\hline RT-373 X GT-2 & $21.10 * * \pm 0.36$ & $-3.26 * * \pm 0.21$ & $-0.49 * \pm 0.09$ & $-7.10 * * \pm 0.28$ & $0.64 \pm 0.81$ \\
\hline JLS-613-1-1 X GT-10 & $18.17 * * \pm 0.49$ & $3.87 * * \pm 0.24$ & $-1.54 * * \pm 0.11$ & $7.87 * * \pm 0.37$ & $9.94 * * \pm 0.74$ \\
\hline MT-10 X GT-2 & $20.16 * * \pm 0.41$ & $-1.38 * * \pm 0.12$ & $8.70 * * \pm 0.04$ & $8.43 * * \pm 0.44$ & $-10.35 * * \pm 0.69$ \\
\hline AT-253 X TKG-22 & $11.18 * * \pm 0.32$ & $-1.90 * * \pm 0.19$ & $-9.55^{* *} \pm 0.17$ & $-10.79 * * \pm 0.49$ & $16.22 * * \pm 0.56$ \\
\hline \multicolumn{6}{|c|}{ Oil content (\%) } \\
\hline TKG-503 X GT-10 & $38.72 * * \pm 0.13$ & $1.32 * * \pm 0.04$ & $10.42 * * \pm 0.34$ & $4.93 * * \pm 0.12$ & $8.50 * * \pm 0 . .27$ \\
\hline RT-373 X GT-2 & $38.85 * * \pm 0.16$ & $5.32 * * \pm 0.06$ & $6.28 * * \pm 0.46$ & $-0.07 \pm 0.015$ & $-5.57 * * \pm 0.33$ \\
\hline JLS-613-1-1 X GT-10 & $43.80 * * \pm 0.11$ & $-4.93 * * \pm 0.05$ & $-0.30 \pm 0.31$ & $-0.47 * * \pm 0.09$ & $-1.53 * * \pm 0.27$ \\
\hline MT-10 X GT-2 & $30.58 * * \pm 0.09$ & $4.32 * * \pm 0.06$ & $12.28 * * \pm 0.28$ & $9.20 * * \pm 0.07$ & $12.37 * * \pm 0.21$ \\
\hline AT-253 X TKG-22 & $40.47 * * \pm 0.11$ & $-0.93 * * \pm 0.04$ & $8.93 * * \pm 0.33$ & $4.87 * * \pm 0.11$ & $8.67 * * \pm 0.33$ \\
\hline
\end{tabular}

For plant height trait, the magnitude of additive gene effects $[d]$ were in negative direction in all the crosses except JLS-613-11 X GT-10, MT-10 X GT-2 and AT-253 X TKG-22 whereas dominance gene effects $[h]$ was in positive direction in TKG-503 X GT10, RT-373 X GT-2.

Among the non-allelic interactions, additive $\mathrm{x}$ additive gene effects $[i]$ were in negative direction in all the crosses except JLS-613-11 X GT-10, MT-10 X GT-2 and AT-253 X TKG-22. Higher value of dominance $x$ dominance gene effects $[l]$ was shown by JLS-613-1-1 X GT-10, AT-253 X TKG-22 and MT-10 X GT-2. Similar findings were also reported by Padma et al., (2012), Jaloth et al., (2014), Ali et al., (2015).

Dominance gene effects $[h]$ were found to be positive and highly significant for number of primary branches per plant in all the crosses except RT-373 X GT-2, number of secondary branches per plant and oil content in all the crosses except JLS-613-1-1 X GT-10, capsule length in all the crosses except MT-10 X GT2 , days to maturity in all the crosses except TKG-503 X GT-10, for number of capsules per plant, seeds per capsule and 1000-seed weight in all the five crosses i.e. TKG-503 XGT-10, RT-373 X GT-2, JLS-613-1-1 X GT-10, MT-10 X GT-2, AT-253 X TKG-22 results indicating the presence of dominance gene effect $[h]$ in the inheritance of these characters. These results are in harmony with the result obtained by Jayalakshmi et al., (2000) and Krishnaiah et al., (2003) for days to maturity; Senthil Kumar and Ganesan (2004) for number of capsules per plant; Gaikwad et al., (2009) for 1000-seed weight; Sumathi and Murlidharan (2010a) for seeds per capsule, Sundari et al., (2012) for number of capsules per plant. Jaloth et al., (2013) for number of branches per plant, 1000-seed weight and oil content.

Among the type of dominance $x$ dominance $[l]$ gene action, positive and highly significant effects were detected for seeds per capsule and days to maturity in all the five crosses except JLS-613-1-1 X GT-10 and AT-253 X TKG-22 and for number of capsules per plant, seed yield per plant and 1000-seed weight in all the five crosses except JLS-613-1-1 X GT10. These results are in conformity with the findings of Yamanura and Nadaf (2009) Sumathi and Murlidharan (2010b) for days to maturity; Parameshwarappa (2009), Prajapati 
et al., (2010) and Sundari et al., (2012) for number of capsules per plant; Jaloth et al., (2013) for 1000 seed weight and oil content.

In regard to the seed yield per plant trait, the additive effect $[d]$ was significant and positive in all the crosses except MT-10 X GT-2. The dominance gene effects $[h]$ were found to be positive and significant for all the crosses except AT-253 X TKG-22. Among the epistatic effects, dominance $\mathrm{x}$ dominance was significant and positive for all the crosses except JLS-613-1-1 X GT-10. These results indicates that seed yield per plant is predominantly controlled by dominance $x$ dominance $[l]$ type interaction effects. The dominance $[h]$ and dominance $\times$ dominance (l) gene effects showed opposite signs, indicating the presence of duplicate dominant epistasis in the expression of this trait. Similar findings were also reported by Krishnaiah et al., (2002), Jaloth et al., (2014), Ali et al., (2015).

Opposite sign of dominance component $[h]$ and dominance $\mathrm{x}$ dominance $[l]$ type of gene effect were recorded for days to $50 \%$ flowering and plant height in all the five crosses, TKG-503 X GT-10, RT-373 X GT-2, JLS-613-1-1 X GT-10, MT-10 X GT-2 and AT-253 X TKG-22; for number of secondary branches per plant in two crosses, RT-373 X GT-2 and JLS-613-1-1 X GT-10; number of capsules per plant in one cross JLS-613-1-1 X GT-10; for days to maturity in three crosses TKG-503 X GT-10, JLS-613-1-1 X GT-10 and AT-253 X TKG-22, seeds per capsule and seed yield per plant in two crosses JLS613-1-1 X GT-10 and AT-253 X TKG-22, 1000-seed weight in one cross JLS-613-1-1 X GT-10; harvest index in four crosses RT-373 X GT-2, JLS-613-1-1 X GT-10, MT-10 X GT-2 and AT-253 X TKG-22 and for oil content in one cross RT-373 X GT-2 which, revealed that duplicate dominant type of epistatic gene action was controlling the inheritance of these traits. Hence, on the basis of significant estimates of gene effect above results suggested that these traits were predominantly under the control of dominance gene effects (h). Similar results have been obtained by Gaikwad et al., (2010) for number of capsules per plant and seeds per capsule; Sumathi and Murlidharan (2010a) for seed yield and days to 50 per cent flowering; Sumathi and Murlidharan (2010b) for days to maturity; Sundari et al., (2012) for number of capsules per plant; Jaloth et al., (2013) for 1000 seed weight and oil content; Jaloth et al., (2014) and Ali et al., (2015) for seed yield per plant, seeds per capsule and plant height. The estimation of gene effects by generation mean analysis indicated that the dominance variance was larger than additive variance for all the characters in all the five crosses.

The additive effects and gene interaction dominance $\times$ dominance $(l)$ or other type digenic complementary gene interaction can be exploited effectively by selection for the improvement the characters. Use of reciprocal recurrent selection or Bi-parental mating suggested improving the characters when both additive and non-additive gene effects are involved in the expression of these traits. Presence of non-additive gene for days to 50 percent flowering, effective primaries/plant, number of capsules/plant, 1000 seed weight, oil content and seed yield/plant indicating that conventional selection procedure may not be effective enough for improvement of yield. Therefore postponement of selection in later generations or intermating among the selected seggregants followed by one or two generations of selfing could be suggested to break the undesirable linkage and allow the accumulation of favourable alleles for the improvement of this trait.

In the present investigation, it was observed that presence of non-additive gene action 
were important for the expression of seed yield and its attributing traits. Among the epistasis, dominance $\mathrm{x}$ dominance $[l]$ gene interactions formed the major part of the genetic variance for the important yield component traits in generation mean analysis. Therefore genetic improvement in the 'seed yield per plant' trait would be easier through indirect selection for a component trait than through direct selection for seed yield itself. These results indicated that epistasis is the integral part of genetic architecture of the present material used in the investigation and breeder cannot ignore it. Hence, it can be stated that, to break the linkage between gene constellations reciprocal recurrent selection or bi-parental mating are the breeding strategies proposed for the improvement of yield and its attributes in sesame.

\section{References}

Ali, K. 2015. Generation mean analysis for yield and yield components in sesame (Sesamum indicum L.). Int. J. Env. 3(4): 111-120.

Anbanandan, V., Anbuselvam, Y. and Ganesan, J. 2006. Genetic architecture of yield and its components in sesame (Sesamum indicum L.). Sesame and Safflower Newsletter. 21: 21-23.

Annonymous. 2015. Agricultural Statistics Division, Directorate of Economics and Statistics, New Delhi, $2^{\text {nd }}$ Advance Estimates.

Ashri, A. 1989. Sesame breeding objectives and approaches. Oil Crops: Sunflower, Linseed and Sesame, Ed. Omran, A., IDRC-MR205E, IDRC, Ottawa.

Ashri, A. 1998. Sesame breeding. Plant Breeding Reviews. 16: 179-228.

Cagrgan, M.I. 2006. Selection and morphological characterization of induced determinate mutants in sesame. Field Crops Res. 96: 19-24.
Cavalli, L.L. 1952. An Analysis of Linkage in Quantitative Inheritance. Lieve, E.C.R. and C.H. Waddington, (Eds.), HMSD, London, pp: 135-144.

Gaikwad, K.B., Lal, J.P. and Kumar, H. 2010. Gene effects for yield and its components in sesame (Sesamum indicum L.). Res. Crops. 6(3): 312-315.

Hayman, B. I. 1958. The separation of epistasis from additive and dominance variation in generation means. Heredity. 12: 371-90.

Jatoth, J.L., Dangi, K.S. and Sudheer, K. 2014. Gene action for quantitative traits through Generation means analysis in sesame (Sesamum indicum). Indian. J. Agric. Sci. 84(11): 1369-75.

Jatoth, J.L., Dangi, K.S., Sagi, S.K., Bhandari, H.R., Tripathi, M.K. and Chaudhary, B. 2013. Estimation of gene effects based on joint scaling test and sequential model fit scheme for quantitative traits in sesame (Sesamum indicum L.). J. Agric. Sci. 5(3): 224-235

Jayalakshmi, V., Rajareddy, C., Hariprasad, R.K. 2000. Combining ability analysis for yield and yield components in sesame. Andhra Agriculture Journal. 47(3 \& 4): 197 -200.

Jinks, J.L. and Jones, R.M. 1958. Estimation of the components of heterosis. Genetics. 43: 223-4.

Kearsey, M. J. and Pooni, H. S. 1996. The Genetic Analysis of Quantitative Traits, 1st edition. Chapman and Hall, London.

Krishnaiah, G., Reddy, R.K. and Reddi, S.M. 2003. Heterosis and combining ability in sesame (Sesamum indicum L.). J. Oilseeds Res. 20(2): 229-233.

Parameshwarappa, S.G. and Salimath, P.M. 2010. Studies on combining ability and heterosis for yield and yield components in sesame (Sesamum indicum L.). Green Farming. 3(2): 9194. 
Prajapati, N.N., Patel, C.G., Patel, K.M. and Prajapati, K.P. 2010. Combining ability for seed yield and its components in sesame (Sesamum indicum L.). Int. J. Plant Sci. 5(1): 180-183.

Senthil, K.P. and Ganesan, J. 2004. Line x tester analysis for combining ability in sesame (Sesamum indicum L.). Sesame and Safflower Newsletter. 17: 17-21.

Sumathi, P. and Muralidharan, V. 2010a. Components of genetic variance and degree of dominance for seed yield attributing traits in sesame (Sesamum indicum L.). J. Oilseeds Res. 27(1): 3133.

Sumathi, P. and Muralidharan, V. 2010b. Inheritance of branching and important biometrical traits in sesame (Sesamum indicum L.). Indian J. Gen. 70(1): 97101.

Sundari, M., Kamala, T. and Rao, Y.V. 2012. Generation mean analysis in sesame (Sesamum indicum L.) Asian J. Agric. Sci. 4(4): 280-286.

Sundari, M.P., Kamala, T. and Rao, Y.V. 2012. Generation mean analysis in Sesamum indicum L. Asian J. Agric.Sci. 4(4): 280-284.

Weiss, E. A. 1983. Oilseed crops. Tropical Agriculture Series, John Wiley \& Sons Incorporated.

Yamanura, K.M. and Nadaf, H.L. 2009. Combining ability and gene action for yield and yield components in sesame (Sesamum indicum L.). Karnataka Agric. Journal. 22(2): 255-260.

\section{How to cite this article:}

Kanak Saxena and Rajani Bisen. 2018. Generation Means Analysis for Quantitative Traits in Sesame (Sesamum indicum L.). Int.J.Curr.Microbiol.App.Sci. 7(08): 18-25. doi: https://doi.org/10.20546/ijcmas.2018.708.003 